\title{
THE SCHEME OF TREATMENT WITH AN INFECTED PATIENT WITH COVID-19
}

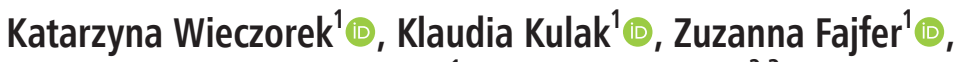 \\ Aleksander Krupski ${ }^{1}$, Lukasz Szarpak ${ }^{2,3}$ (B) \\ ${ }^{1}$ Student's Journal Club, Lazarski University, Warsaw, Poland \\ ${ }^{2}$ Comprehensive Cancer Center in Bialystok, Poland \\ ${ }^{3}$ Polish Society of Disaster Medicine, Warsaw, Poland
}

KEY WORDS: SARS-CoV-2, COVID-19, pathogen, healthcare workers, hospital, communication route, pandemic, management, infection control

Disaster Emerg Med J 2020; 5(2): 112-113

To the Editor,

SARS-CoV-2, also referred to as CoV-19, can cause severe acute respiratory diseases (COVID-19), with a serious infection of the lower respiratory tract followed by bronchitis, pneumonia and fibrosis [1]. The severity of the disease depends on the efficiency of the immune system which, if it is weak, cannot stem the infection and its symptoms [2]. Health workers are at the front line of the COVID-19 outbreak response and as such are exposed to hazards that put them at risk of infection. Hazards include pathogen exposure, long working hours, psychological distress, fatigue, occupational burnout [3]. Data from China's National Health Commission show that more than 3300 healthcare workers have been infected as of early March and, according to local media, by the end of February at least 22 had died. In Italy, 20\% of responding health-care workers were infected, and some have died [4].

The most susceptible to infection are those forming the medical sector, especially healthcare workers, i.e. physicians, nurses or administration staff. Thus, they should be aware of the necessity of correct segregation of possibly infected patient with COVID-19 (triage) to reduce the number of contacts. This segregation could be performed remotely, by telephone or online, which may effectively enable to pre-assess symptoms of patients and to identify those of COVID-19. Such an assessment may allow for the correct preparation of both medical staff and others for the possible infectious contact.
Getting the hospital ready to receive patients is crucial. The flow must be carried out in accordance with the principle of "three zones and two passage". Which in practice means unilateral entry and exit, and between them should be taken into account contaminated zone, potentially contaminated and clean. The communication route should also include the research room, laboratory, observation room and resuscitation room in turn [5].

In order to protect workers and patients, correct assessment of the risk of the likelihood of COVID-19 infection, including the clinical review, epidemiological and travel history needs to be completed. It would allow for evaluation of the risk of infection, basing on signs and symptoms [6]. Basing on current knowledge on the transmission of how COVID-19 spreads. Therefore, medical staff should wear personal protective equipment and treat every patient as potentially infectious - especially in emergency medical conditions.

\section{REFERENCES}

1. Smereka J, Szarpak L. The use of personal protective equipment in the COVID-19 pandemic era. Am J Emerg Med. 2020 [Epub ahead of print], doi: 10.1016/j.ajem.2020.04.028, indexed in Pubmed: 32305157.

2. Conti $P$, Gallenga $C E$, Tetè $G$, et al. How to reduce the likelihood of coronavirus-19 (CoV-19 or SARS-CoV-2) infection and lung inflammation mediated by IL-1. J Biol Regul Homeost Agents. 2020 [Epub ahead of print]; 34(2), doi: 10.23812/Editorial-Conti-2, indexed in Pubmed: 32228825. 
3. Mathieu F. Occupational hazards: compassion fatigue, vicarious trauma and burnout. Can Nurse. 2014; 110(5): 12-13, indexed in Pubmed: 25076569.

4. Ferioli M, Cisternino C, Leo V, et al. Protecting healthcare workers from SARS-CoV-2 infection: practical indications. Eur Respir Rev. 2020; 29(155), doi: 10.1183/16000617.0068-2020, indexed in Pubmed: 32248146.
5. Ayebare RR, Flick R, Okware S, et al. Adoption of COVID-19 triage strategies for low-income settings. Lancet Respir Med. 2020; 8(4): e22, doi: 10.1016/S2213-2600(20)30114-4, indexed in Pubmed: 32171063.

6. Centor RM, Marrazzo J. Web Exclusive. Annals On Call - Protecting Health Care Workers From COVID-19. Ann Intern Med. 2020 [Epub ahead of print], doi: 10.7326/A20-0002, indexed in Pubmed: 32227236. 